\author{
Esperanza Gutiérrez-Redomero, ${ }^{1}$ Ph.D.; Juan A. Quirós, ${ }^{2}$ M.Sc.; Noemi Rivaldería, ${ }^{1}$ M.Sc.; \\ and María C. Alonso, ${ }^{3}$ Ph.D.
}

\title{
Topological Variability of Fingerprint Ridge Density in a Sub-Saharan Population Sample for Application in Personal Identification
}

\begin{abstract}
Variability in ridge density in a sub-Saharan population sample was studied by counting ridges in three fingerprint areas (two distal regions, radial and ulnar, and one proximal region) on the epidermal surface of the distal phalanx. Study material was obtained from the fingerprint impressions of 100 male sub-Saharan subjects aged between 18- and 48-years old. The results were compared with those obtained from a Spanish population sample. Sub-Saharan males presented lower ridge density than Spanish males in the distal regions (radial and ulnar) of all fingers, whereas differences in the proximal region were only observed on some fingers. Using the differences observed between these populations, the likelihood ratio for inferring membership of one of the populations from a fingerprint of unknown origin was calculated; therefore, a ridge density of 14 or less for both areas (ulnar and radial), support an origin sub-Saharan versus Spanish population.
\end{abstract}

KEYWORDS: forensic science, forensic anthropology, fingerprints, dermatoglyphics, ridge density, sub-Saharan, Spanish

The study of dermatoglyphics involves analyzing the epidermal ridges found on the surface of the palms, soles, fingers, and toes of all primate species, including humans (1). Dermatoglyphics have been used extensively in bioanthropology, genetics, and evolutionary studies to characterize populations, to analyze the nature and origin of human variability, to assess population structure, and for interpopulation microdifferentiation (2-5).

Dermatoglyphics are polygenic characteristics with a possible limited environmental influence in the first few months of embryonic life $(6,7)$. Although some methodological and genetic questions remain unresolved $(4,8,9)$, a detailed history of the study of dermatoglyphics in human populations has demonstrated the usefulness of the information obtained from these characteristics in understanding the evolution and genetic structure of human populations (10-12), in characterizing syndromes and diseases $(6,13-17)$, and in personal identification in the field of forensic science (18-25).

The formation of epidermal ridges occurs very early on in prenatal development, between the 10th and 16th week of gestation: by the sixth month, the dermal papillae ridges are considered fully developed (26-31). Once formed, and in the absence of lesions, these ridges will remain essentially unchanged

${ }^{1}$ Departamento de Zoología y Antropología Física, Instituto Universitario de Investigación en Ciencias Policiales, Universidad de Alcalá, Alcalá de Henares, Madrid, Spain.

${ }^{2}$ Unidad Orgánica de la Policía Judicial de la Guardia Civil, Granada, Spain.

${ }^{3}$ Departamento de Matemáticas, Instituto Universitario de Investigación en Ciencias Policiales, Universidad de Alcalá, Alcalá de Henares, Madrid, Spain.

Received 23 July 2011; and in revised form 30 Jan. 2012; accepted 11 Feb. 2012 throughout the life of the individual. Thus, ridge number is independent of age, and ridges tend to increase in size rather than in number as the body in general, and hands and feet in particular, grow (32-34). Nevertheless, age is a factor which affects fingerprint recognition, as previous studies have shown that the elderly population has a higher chance of a mismatch compared with the younger population (35).

Although numerous studies have been carried out on the dermatoglyphics of human populations, some of their inherent characteristics have received more attention than others. Thus, features such as main pattern type, pattern intensity index or ridge count have been widely studied (see bibliographies in 36-38), whereas other features, such as the minutiae $(7,19,20,39-44$, among others) or epidermal ridge breadth have received comparatively less attention, despite being of considerable interest due to their direct relevance in personal identification. Epidermal ridge breadth or thickness is determined by two parameters: (i) ridge width, and (ii) distance between ridges, and is a characteristic which presents topological, finger, and gender variability as well as differences between populations $(1,15,45-50)$. Recently, some studies have explored the forensic applications of this feature for inferring the gender of an individual from fingerprints of an unknown origin (51-55).

Fingerprint recognition is one of the most widely used biometric systems and its use has also extended to personal authentication and government-to-citizen applications. Fingerprint recognition systems must be capable of handling fingerprints and palmprints from a diverse range of demographics. However, neither the impact of gender on such systems nor the possible differences among human populations have received much attention from the research community $(50,56)$. Therefore, the aim of this study was to analyze topological and bimanual 
variability in epidermal ridge density using the fingerprints taken from a sub-Saharan population sample. In addition, this sample was compared with a Spanish population sample (53), collected and analyzed using the same study methodology, to identify criteria for discriminating between the populations.

\section{Materials and Methods}

The material used for this study was obtained from fingerprint records held by the police. The fingerprints had been taken using the ink and roll method at the laboratory of the Judicial Police Unit at the Civil Guard Headquarters (Unidad Orgánica de la Policốa Judicial de la Comandancia de la Guardia Civil) in Granada (Spain). The sample consists of 100 males from the north west sub-Saharan region, of which 72 individuals were from Senegal, 15 from Mali, seven from Nigeria, two from Ghana, one from Guinea, one from Guinea Bissau, one from Sierra Leone, and one from Gambia (Fig. 1). A total of 1000 fingerprints were analyzed. As ridge breadth changes as the body grows, the sample was limited to adult subjects aged between 18- and 48-years old.

As is well-known, ridge breadth on finger and palmprints varies according to the amount of pressure applied when taking samples. Therefore, this characteristic was analyzed in accordance with the definition given by Penrose (57), namely, "as the distance between the center of one epidermal furrow and the center of the next furrow along a line at right angles to the direction of the furrow" (p. 1). Traditionally, indirect methods have been used to measure true ridge breadth, where the number of ridges transversely crossing a defined line is counted and ridge breadth is obtained by dividing the two figures $(46,47)$. With this method of assessment, it is necessary to distinguish between breadth and printed ridge (line) width as the black line is a mere negative of the ridge top.

To assess ridge density, or the number of ridges occupying a defined area, a ridge count was carried out diagonally on a square measuring $5 \times 5 \mathrm{~mm}$, according to the method described by Acree (51). This provides the number of ridges/7.07 $\mathrm{mm}$ on the fingertip surface of an area located on the radial side of the distal region of each finger. In this study, we applied the methodology proposed by Gutiérrez-Redomero et al. (53) (Fig. 2) to locate the ridge count areas. Therefore, we increased the number of ridge count areas related to Acree's method (51) by including two additional areas, one on the ulnar side of the distal region of the fingertip and the other on the proximal region. To locate the

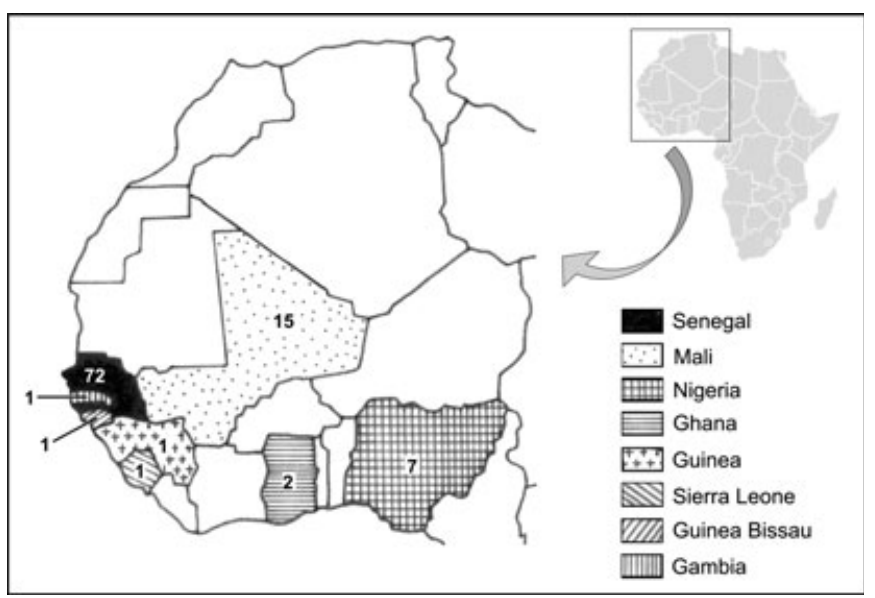

FIG. 1-Map of North West Africa showing the origin sample. three-count areas, the fingerprint is divided into four sectors by two perpendicular axes that cross two ridges above the center of the type of pattern (Fig. 2), with the horizontal line positioned parallel to the interphalangeal joint. In the case of arches without a defined nucleus, the axes intersect at the center of the dactylogram on top of the arch (Fig. 2).

To facilitate counting, the ridge count was carried out using images enlarged to 16 times their original size, on which an area of $20 \times 20 \mathrm{~mm}$ was defined. The fingers were assigned the numbers $1-10$, starting from the right thumb or finger $1(\mathrm{~F} 1)$ and ending with the left little finger or finger 10 (F10).

The sample was statistically analyzed using SPSS 15.0 (IBM Corporation, Armonk, NY) and Statistica 7 software (StatSoft, Tulsa, OK). The ridge counts for the three areas (radial, ulnar, and proximal) of all 10 fingers of each individual enabled the mean for each area and each finger to be calculated. In addition, the mean ridge density for each area (radial, ulnar, and proximal) for all 10 fingers was calculated for each individual. The results obtained were compared with those for a Spanish population sample, previously published by Gutiérrez-Redomero et al. (53). Differences between the two populations were analyzed for the three areas: individually (mean for each area), and for both hands (mean for the areas of the right hand and the left hand). The sample was statistically analyzed by obtaining total and group descriptive values for the areas assessed, and comparing them to determine the significance of these differences. To this end, the Student's $t$-test and Wilcoxon's test for related samples were used. We applied analysis of variance to determine how the mean ridge density by hand is affected by two factors: the area (radial, ulnar, and proximal) and the population (Spanish and sub-Saharan). However, when the ridge density by finger (noncontinuous response) was compared we used nonparametric methods as the K-related samples (Friedman test). Frequencies for different types of patterns and their relationship with ridge density were calculated. We used the test for independence of characteristics (chisquare) to study the relationship between the type of pattern (arch-A, radial loop-RL, ulnar loop-UL, and whorl-W) and fingers (F1-F10). When dependence was detected, we applied a simple correspondence analysis (CA) to explain where this dependence was located on a two-way contingency table; that is, a frequency table with only two categorical variables.

In addition, mean ridge density by area for all 10 fingers was calculated for each subject, and the frequency distribution thus obtained was then used to calculate the likelihood ratio (LR), to obtain the probability of inferring the donor's population of origin from ridge density values (58), where RD is ridge density, $\mathrm{C}$ the Spanish donor, and $\mathrm{C}^{\prime}$ the sub-Saharan donor.

$\mathrm{LR}=$ probability of observing a given ridge density if the donor was Spanish (C)/probability of observing a given ridge density if the donor was sub-Saharan $\left(C^{\prime}\right)=P(R D \mid C) / P\left(R D \mid C^{\prime}\right)$.

The value of $\mathrm{LR}$ gives the strength of support for one of the hypotheses: $C$ or $C^{\prime}$. Posterior probabilities $\mathrm{P}(\mathrm{C} \mid \mathrm{RD})$ and $\mathrm{P}\left(\mathrm{C}^{\prime} \mid\right.$ RD) were calculated using Bayes' theorem (58). Information obtained from both LR computations and posterior probabilities were used to show favored odds for support of the most likely hypothesis for a given ridge density $\mathrm{P}(\mathrm{RD} \mid \mathrm{C})$ and $\mathrm{P}\left(\mathrm{RD} \mid \mathrm{C}^{\prime}\right)$. The prior probability of Spanish $\mathrm{P}(\mathrm{C})$ and sub-Saharan $\mathrm{P}\left(\mathrm{C}^{\prime}\right)$ depends on the degree of evidence that we have for the donor.

\section{Results}

Ridge density was assessed in three areas: two distal regions (radial and ulnar) and one proximal region. The mean ridge 


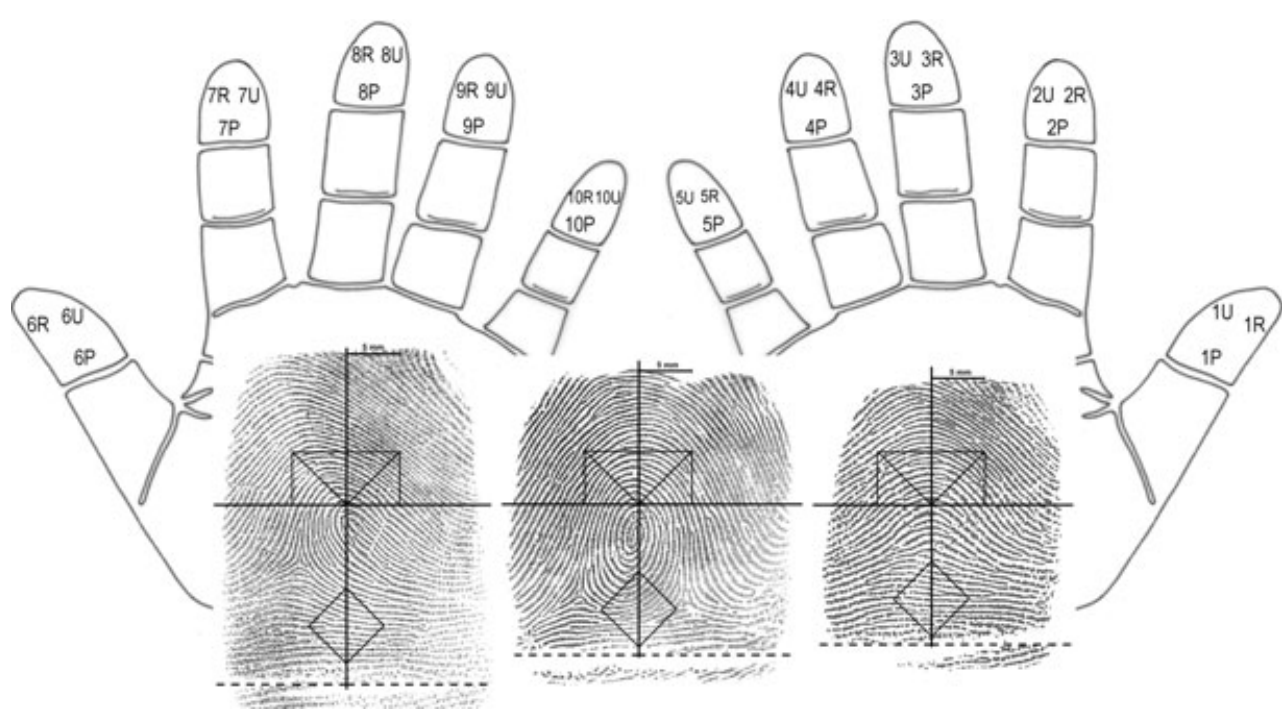

FIG. 2-Location of count areas for different types of patterns (loop, whorl, and arch). Distal area: ulnar (U) and radial (R). Proximal area (P). Fingers $(\mathrm{i}=1, \ldots, 10)$.

density for all 10 fingers by area showed significant differences across the three areas (Table 1). Figure 3 gives the values obtained by finger and area (radial, ulnar, and proximal). On all fingers, both the radial and ulnar areas of the distal region presented a higher ridge density than the proximal region, and this was statistically significant. The thumbs (F1 and F6) presented the lowest ridge density on both the ulnar and radial areas of both hands, while the ring fingers (F4 and F9) presented the highest ridge density, again on both hands (Fig. 3). In contrast, in the proximal region it was the little fingers (F5 and F10) which presented the lowest density, and the thumbs (F1 and F6) which presented the highest. The right hand presented a significantly higher ridge density and therefore, narrower ridges, on the ulnar side, whereas ridge density on the left hand was significantly higher and therefore ridges were narrowest, on the radial side (Fig. 3).

Ridge density in all three areas correlated positively and significantly: thus, individuals who presented a high or low ridge density in one of the areas also presented this characteristic in the other two areas.

The right hand thumb (F1) and the left hand middle finger (F8) presented the greatest differences between the radial and ulnar areas in ridge density. In contrast, the fingers presenting the least difference in ridge density were the right hand middle finger (F3) and the left hand thumb (F6).

Significant differences between fingers for the radial and ulnar areas are shown in bold in Table 2. Significant differences

TABLE 1-Descriptive statistics of ridge density when subdivided by areas.

\begin{tabular}{lccc}
\hline & \multicolumn{3}{c}{ Sub-Saharan } \\
\cline { 2 - 4 } Areas & Ulnar & Radial & Proximal \\
\hline$n$ & 100 & 100 & 100 \\
Mean & $14.51^{\dagger}$ & $14.33^{\dagger}$ & $12.07^{*}$ \\
SD & 1.29 & 1.22 & 1.15 \\
Minimum & 11.9 & 11.4 & 9.6 \\
Maximum & 17.4 & 17.53 & 16.7 \\
\hline
\end{tabular}

*Ulnar-proximal and radial-proximal $(p<0.001)$.

†Ulnar-radial $(p<0.05)$. between fingers, compared two by two for the radial area, are shown in the bottom left-hand side (in darker type), and the same data are given for the ulnar area (in lighter type) in the bottom right-hand side. For example, it can be seen that on the right hand, the radial areas of the thumb (F1) and the index finger (F2) present significant differences from the radial areas of all the other fingers, whereas on the left hand, although the radial area of the thumb (F6) also presents differences from all the other fingers, the index finger (F7) presents them from all except the right hand middle finger (F3) and little finger (F5). As regards the ulnar area, no significant differences were found between homologous fingers for ridge density. Thus, for example, the thumbs of both hands (F1 and F6) presented significant differences from all other fingers except their homologue.

The frequencies found for the main types of patterns for each finger (arches, radial loops, ulnar loops, and whorls) are shown in Fig. 4a. The ulnar loop (UL) was the most frequent pattern followed by the whorl (W), while the arch (A) and the radial loop (RL) presented considerably lower frequencies. All homologous fingers except the ring fingers (F4 and F9) presented a similar frequency distribution. Whorls were the most frequent pattern type on both index fingers (F2 and F7) and on the right hand ring finger $(\mathrm{F} 4)$, whereas ulnar loops were the most frequent pattern type on the other fingers. Radial loops were only found on the index fingers of both hands (F2 and F7) and the right hand middle finger (F3). Arches were more frequent on the index fingers of both hands (F2 and F7) and on the left hand thumb (F6).

Significant dependence was found $\left(\chi^{2}=156.13 \mathrm{df}=27\right.$; $p$-value $<0.0001)$ between the general patterns and the fingers. The CA shown in Fig. $4 b$ explains $93.63 \%$ of the inertia. The first dimension separates the whorls, the arches and the radial loops from the ulnar loops. The second dimension separates the thumbs (F1 and F6) and ring fingers (F4 and F9) from the index (F2 and F7), middle (F3 and F8), and little (F5 and F10) fingers.

No association was found between epidermal ridge density and pattern type for either the radial or ulnar areas with the exception of the left hand thumb (F6), where ridge density was significantly higher in whorls than in arches in the ulnar area, with the whorls consequently presenting narrower ridges. In contrast, 


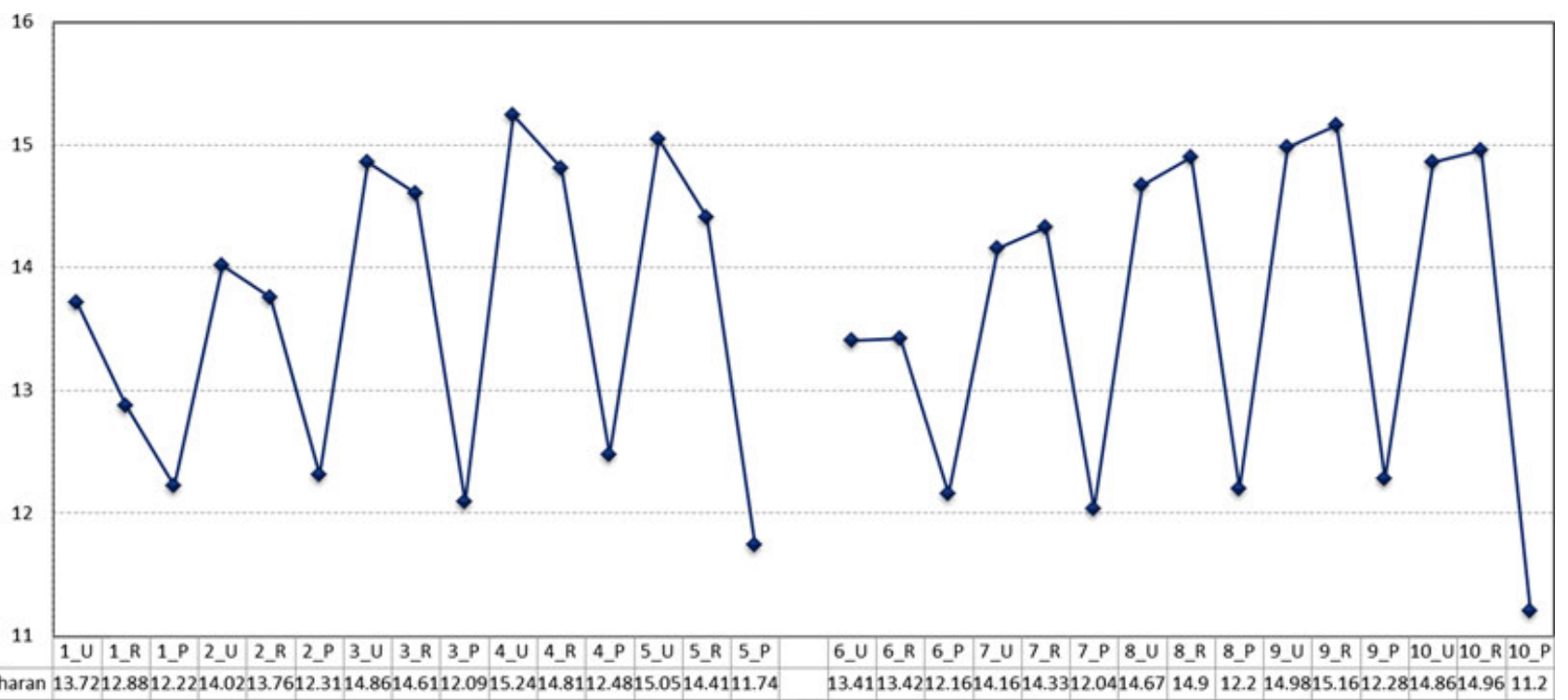

FIG. 3-Mean ridge density for each area for 10 fingers. $U$, ridge density ulnar; $R$, ridge density radial; $P$, ridge density proximal. Fingers $(\mathrm{i}=1, \ldots, 10)$.

TABLE 2-Differences between fingers for the radial and ulnar areas.

\begin{tabular}{|c|c|c|c|c|c|c|c|c|c|c|c|}
\hline & 1 & 2 & 3 & 4 & 5 & 6 & 7 & 8 & 9 & 10 & \\
\hline 1 & & 0.091 & $<0.001$ & $<0.001$ & $<0.001$ & 0.117 & $<0.05$ & $<0.001$ & $<0.001$ & $<0.001$ & \\
\hline 2 & $<0.001$ & & $<0.001$ & $<0.001$ & $<0.001$ & $<0.001$ & 0.548 & $<0.01$ & $<0.001$ & $<0.001$ & \\
\hline 3 & $<0.001$ & $<0.001$ & & $<0.01$ & 0.250 & $<0.001$ & $<0.001$ & 0.413 & 0.308 & 0.423 & \\
\hline 4 & $<0.001$ & $<0.001$ & 0.256 & & 0.234 & $<0.001$ & $<0.001$ & $<0.01$ & 0.117 & 0.117 & \\
\hline 5 & $<0.001$ & $<0.01$ & 0.268 & $<0.05$ & & $<0.001$ & $<0.001$ & $<0.05$ & 0.505 & 0.360 & Ulnar \\
\hline 6 & $<0.01$ & $<0.05$ & $<0.001$ & $<0.001$ & $<0.001$ & & $<0.001$ & $<0.001$ & $<0.001$ & $<0.001$ & \\
\hline 7 & $<0.001$ & $<0.01$ & 0.089 & $<0.05$ & 0.629 & $<0.001$ & & $<0.001$ & $<0.001$ & $<0.001$ & \\
\hline 8 & $<0.001$ & $<0.001$ & 0.128 & 0.501 & $<0.01$ & $<0.001$ & $<0.001$ & & $<0.05$ & 0.176 & \\
\hline 9 & $<0.001$ & $<0.001$ & $<0.01$ & $<0.05$ & $<0.001$ & $<0.001$ & $<0.001$ & 0.078 & & 0.384 & \\
\hline 10 & $<0.001$ & $<0.001$ & $<0.05$ & 0.229 & $<0.01$ & $\begin{array}{l}<\mathbf{0 . 0 0 1} \\
\text { Radial }\end{array}$ & $<0.001$ & 0.593 & 0.298 & & \\
\hline
\end{tabular}

The bold values represent significant differences between the density of ridges of the fingers $(i=1, \ldots, 10)$ by area (radial and ulnar) at the $95 \%$ confidence level.

significant differences in ridge density in the proximal region were observed on all fingers, with whorls presenting higher ridge densities than all other types of pattern (ulnar loops, radial loops, and arches).

Figure 5 gives the mean ridge densities obtained for all three fingerprint areas for each finger from the sub-Saharan population sample studied, compared with those obtained from a Spanish population sample studied by Gutiérrez-Redomero et al. (53). The sub-Saharan sample presented a significantly lower ridge density than the Spanish sample for both the radial and ulnar areas of all fingers. A means comparison showed that ridge density in the Spanish population sample was significantly higher for all the radial areas of all fingers. However, although the Spanish sample also presented higher ridge densities in the ulnar area of all fingers, these differences were not significant in the case of the right hand thumb (F1) or index finger (F2). In contrast, although the Spanish sample presented lower ridge density than the sub-Saharan population sample in the proximal region of all fingers except both little fingers (F5 and F10) and the right hand thumb (F1), these differences were only significant for the middle fingers of both hands (F3 and F8) and the left hand ring finger (F9).

Comparing ridge density in the radial and ulnar areas of both populations, it was observed that while the sub-Saharan population presented a different pattern for each hand (ridge density on the right hand was higher in the ulnar area, whereas on the left hand it was higher in the radial area), the Spanish population presented the same pattern for both hands, with ridge density being highest in the radial areas of both hands.

A comparison between the left and right hand of mean ridge density in all three areas revealed that the Spanish population presented higher ridge density than the sub-Saharan sample in the radial and ulnar areas (Fig. 6). Differences between both hands for the three areas were statistically significant.

Ridge density frequency distribution for both populations is given in Fig. 7. In the sub-Saharan population, ridge count variability for the three areas studied ranged from 9 ridges $/ 25 \mathrm{~mm}^{2}$ to 17 ridges $/ 25 \mathrm{~mm}^{2}$, and for the Spanish population, from 8 ridges $/ 25 \mathrm{~mm}^{2}$ to 19 ridges $/ 25 \mathrm{~mm}^{2}$. These distributions were then used to calculate ridge density probabilities, to determine the likelihood ratio and posterior probabilities. This in turn makes it possible to estimate the most likely origin, given a determined number of ridges on the fingerprint, of an individual thought to come from one of these two populations (Tables 3 and 4). We obtained that 14 ridges $/ 7.07 \mathrm{~mm}$ or less have an LR $<1$ for both areas (ulnar and radial), this means that the LR support an origin sub-Saharan population, nevertheless 15 ridges $/ 25 \mathrm{~mm}^{2}$ or more have an LR $>1$ also for both areas (ulnar and radial), this means that the LR supports an origin Spanish population. The results show that depending on the prior proba- 
a
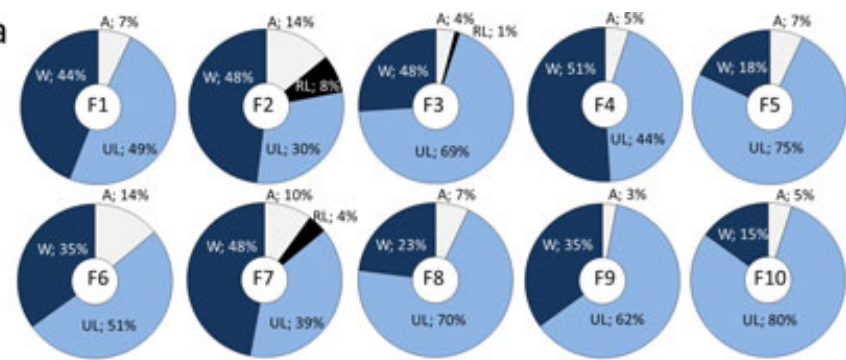

\section{b}

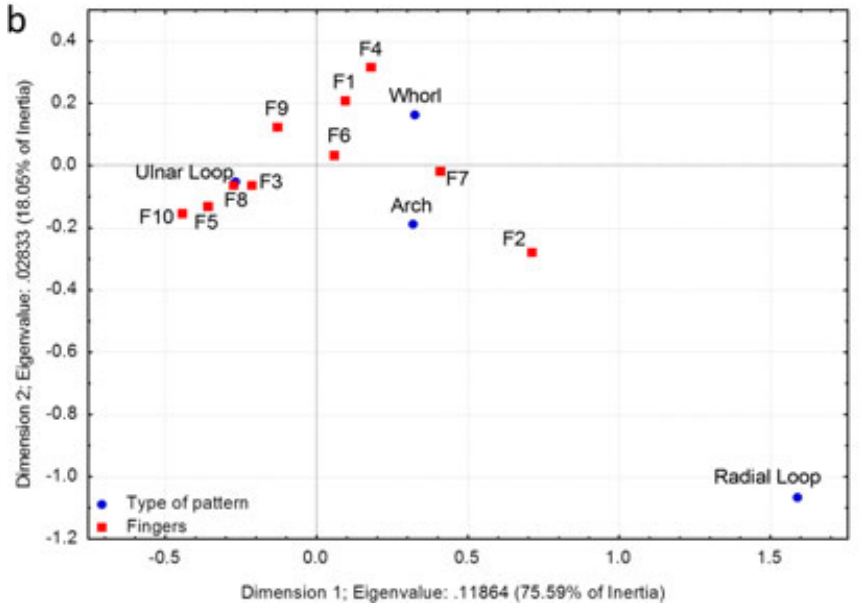

FIG. 4-(a) Frequencies for the type of patterns by finger, F: finger $(\mathrm{i}=1, \ldots, 10)$. (b) Analysis of correspondence between general patterns and the fingers.

bilities of sub-Saharan African men and Spanish men, the favored odds change. Our results show that given the same prior probability for both populations, $\mathrm{P}(\mathrm{C})=\mathrm{P}\left(\mathrm{C}^{\prime}\right)=0.5$, if a fingerprint presents a ridge count of 14 ridges $/ 7.07 \mathrm{~mm}$ or less on either the radial or ulnar areas, it was most probably made by a sub-Saharan male. However, if the ridge count for the same areas is 15 ridges $/ 7.07 \mathrm{~mm}$ or more, the fingerprint was most probably made by a Spanish male. Similarly, the posterior probabilities for the other ridge counts in both areas were also obtained (Tables 3 and 4). As the proximal region did not present significant differences between the fingers of the two populations studied, it was not assessed. The results show that posterior probabilities may vary, depending on the prior probability. Thus, in a situation where the prior probability is $\mathrm{P}(\mathrm{C})=0.7$ and $\mathrm{P}\left(\mathrm{C}^{\prime}\right)=0.3(70 \%$ Spanish population and $30 \%$ sub-Saharan population), the discrimination threshold for the radial area does not change but that of the ulnar area does. Consequently, in this case, a ridge count of 13 ridges $/ 25 \mathrm{~mm}^{2}$ or more would indicate a higher probability that the fingerprint was made by a Spanish male (Table 4).

\section{Discussion}

Together with morphological, molecular, and biochemical markers, dermatoglyphics have traditionally been used in physical anthropology to explore affinities and differences between human groups (see bibliographies in 4,36-38).

Those studies to date which have evaluated differences in ridge density have been based on the traditional method for counting ridges (number of ridges which cross a line drawn from the delta or triradius to the center, without considering the point of origin or termination of the ridges) (1). This model does not permit an assessment of topological differences in ridge density on the same finger, or of topological differences in patterns without a triradius or delta, such as arches. Therefore, the study presented here is the first to use the methodology described with an African population to conduct a topological assessment of all types of fingerprint patterns. The variability observed in ridge density in the three areas studied reflects differences in ridge breadth on the fingerprint surfaces of the sample studied. These differences show a distribution pattern of higher density, and thus, narrower ridges, in the radial and ulnar areas of the distal region. In contrast, a considerably lower ridge density was observed in the proximal region, reflecting the presence of

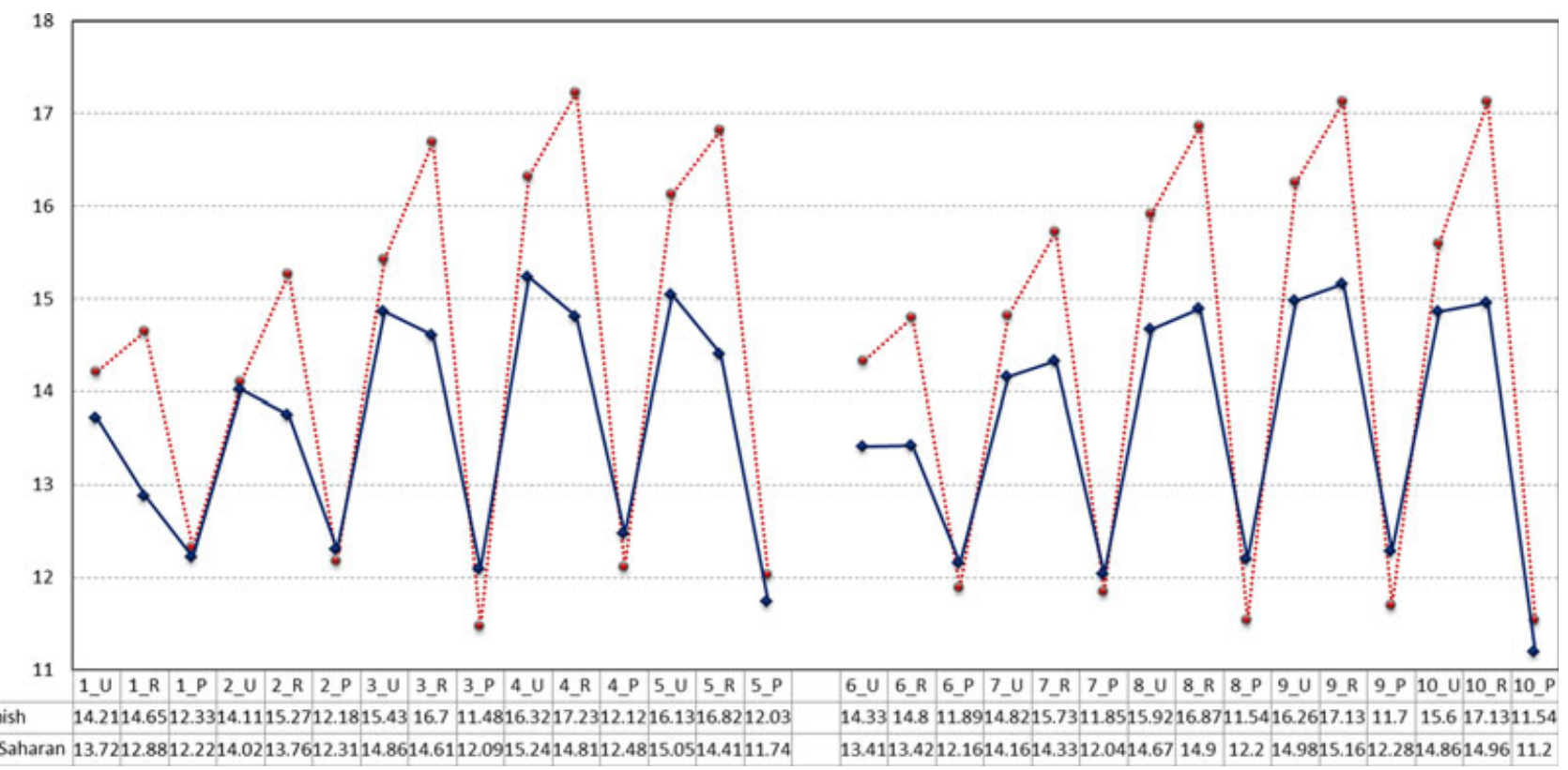

FIG. 5-Mean ridge density for each area for 10 fingers. Finger $(\mathrm{i}=1, \ldots, 10), U$, ridge density ulnar; $R$, ridge density radial; $P$, ridge density proximal. 


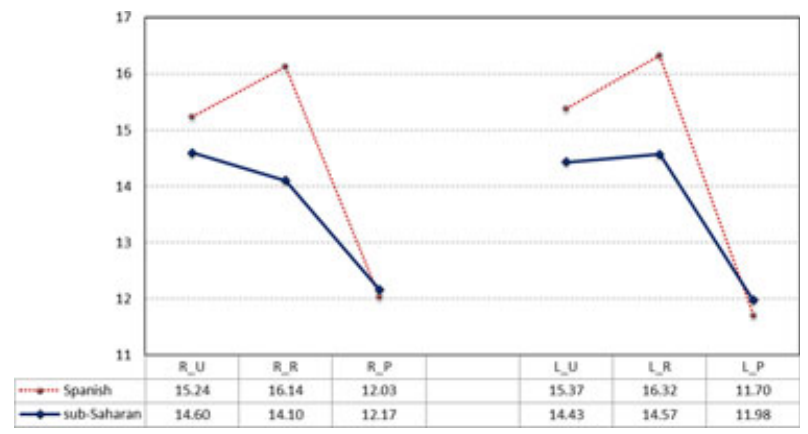

FIG. 6-Mean ridge density for each area for the fingers (right hand and left hand). $R_{-} U$, ridge density in the ulnar of the right hand; $L_{-} U$, ridge density in the ulnar area of the left hand; $R \_R$, ridge density in the radial area of the right hand; $L_{-} R$, ridge density in the radial area of the left hand; $R \_P$, ridge density in the lower area of the right hand; $L \_P$, ridge density in the lower area of the left hand.

thicker ridges in this fingerprint region. These results concur with findings for the Spanish population, although the differences observed between the distal and proximal regions are smaller in the sub-Saharan sample, revealing greater homogeneity in ridge thickness on the fingerprint surface of this population. Surprisingly, however, the topological distribution patterns on both hands observed in the sub-Saharan population did not mirror each other, unlike those observed in the Spanish population sample (Fig. 7).

The distal-proximal gradient observed for ridge breadth on the distal phalanges of the Spanish and sub-Saharan samples has already been reported by Cummins et al. (46) and Ohler and Cummins (47), who described the existence of a topological distal-proximal gradient from the distal phalange of the fingers to the proximal region of the palm of the hand. It is possible that this lower ridge density reflects the presence of thicker ridges: however, it is also possible that it is the consequence of wider grooves, or both characteristics together. Further research which specifically explores these hypotheses is required.

Statistically significant differences were found between ridge density in the radial and ulnar areas, on all fingers. Differences between radial and ulnar ridge counts on fingers have also been found using traditional ridge count methods with several populations (6,59-65, among others). As Jantz and Owsley (59) have pointed out, this suggests that the radial and ulnar areas of fingers are, apparently, responding to different developmental instructions, thus, justifying the use of radial and ulnar ridge counts as independent variables in a dermatoglyphic analysis, and supporting a topological classification system, at least as regards its application to the fingers.

In past decades, various studies have been conducted on subSaharan populations which have demonstrated certain geographic distribution patterns as regards finger and palm dermatoglyphics (60,65-76, among others). The frequencies recorded for the main types of patterns in this study are in agreement with those described for other population groups from the west of Africa. As regards ridge density, we did not find an association between ridge density in the distal region (radial and ulnar areas) and the type of pattern (arch, radial loop, ulnar loop, and whorl). However, ridge density in the proximal region did present significant differences on all fingers, with a higher density being found in whorls than in ulnar loops. These results coincide with those found for the Spanish population (53).

A comparative analysis of the sub-Saharan and Spanish population samples (53) revealed significant differences in ridge density. The sub-Saharan sample presented a lower ridge density in all the areas studied, demonstrating the existence of thicker crests over the entire fingerprint surface. These results coincide with those found by Jantz and Parham (77), who evaluated palm
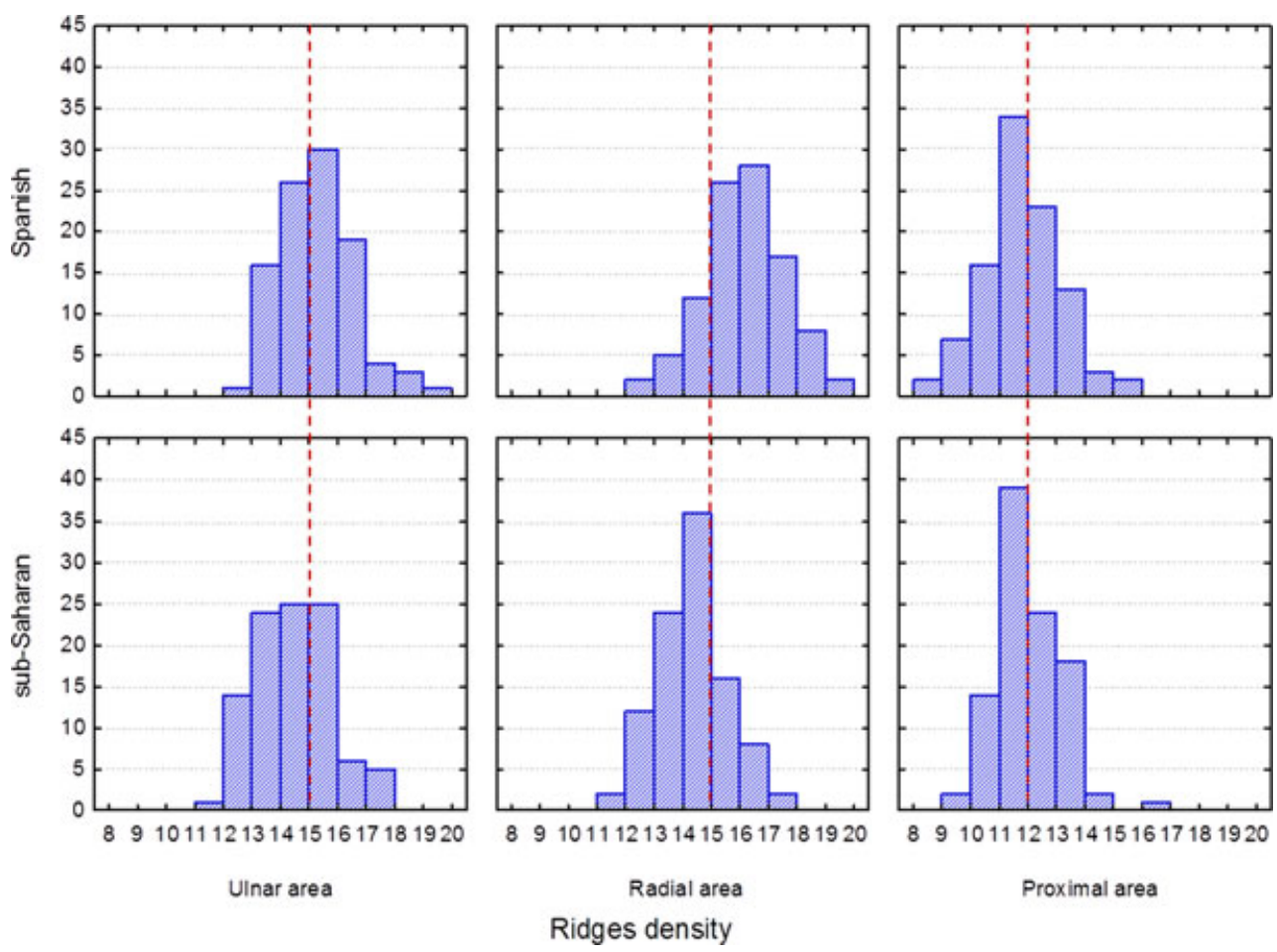

FIG. 7-Frequency distribution of dermal ridge density. sub-Saharan, $\mathrm{n}=100$, Spanish, $\mathrm{n}=100(53)$. 
TABLE 3-Data of probability densities and likelihood ratios derived observed ridge in radial area. Spanish (C) and sub-Saharan $\left(C^{\prime}\right)$.

\begin{tabular}{|c|c|c|c|c|c|}
\hline \multirow[b]{2}{*}{ Ridge Density (RD) } & \multicolumn{2}{|c|}{ Probability Densities } & \multirow[b]{2}{*}{$\begin{array}{l}\text { Likelihood Ratio } \\
\mathrm{P}(\mathrm{RD} \mid \mathrm{C}) / \mathrm{P}\left(\mathrm{RD} \mid \mathrm{C}^{\prime}\right)\end{array}$} & \multicolumn{2}{|c|}{ Favored Odds } \\
\hline & Spanish $\mathrm{P}(\mathrm{RD} \mid \mathrm{C})$ & Sub-Saharan $\mathrm{P}\left(\mathrm{RD} \mid \mathrm{C}^{\prime}\right)$ & & $\begin{array}{c}\mathrm{P}(\mathrm{C})=0.5 \\
\mathrm{P}\left(\mathrm{C}^{\prime}\right)=0.5 \\
\mathrm{P}(\mathrm{C} \mid \mathrm{RD}) \mathrm{P}\left(\mathrm{C}^{\prime} \mid \mathrm{RD}\right)\end{array}$ & $\begin{array}{c}\mathrm{P}(\mathrm{C})=0.7 \\
\mathrm{P}\left(\mathrm{C}^{\prime}\right)=0.3 \\
\mathrm{P}(\mathrm{C} \mid \mathrm{RD}) \mathrm{P}\left(\mathrm{C}^{\prime} \mid \mathrm{RD}\right)\end{array}$ \\
\hline$<13$ & 0.07 & 0.36 & 0.194 & Spanish $(0.16)<$ sub-Sah $(0.84)$ & Spanish $(0.31)<$ sub-Sah $(0.69)$ \\
\hline 14 & 0.11 & 0.36 & 0.306 & Spanish $(0.23)<$ sub-Sah $(0.77)$ & Spanish $(0.42)<$ sub-Sah $(0.58)$ \\
\hline 15 & 0.25 & 0.17 & 1.471 & Spanish $(0.60)>$ sub-Sah $(0.40)$ & Spanish $(0.77)>$ sub-Sah $(0.23)$ \\
\hline 16 & 0.21 & 0.09 & 2.333 & Spanish $(0.70)>$ sub-Sah $(0.30)$ & Spanish $(0.84)>\operatorname{sub}-S a h(0.16)$ \\
\hline$>17$ & 0.36 & 0.02 & 18.000 & Spanish $(0.95)>$ sub-Sah $(0.05)$ & Spanish $(0.98)>$ sub-Sah $(0.02)$ \\
\hline
\end{tabular}

TABLE 4-Data of probability densities and likelihood ratios derived observed ridge in ulnar area. Spanish (C) and sub-Saharan ( $\left.C^{\prime}\right)$.

\begin{tabular}{|c|c|c|c|c|c|}
\hline \multirow[b]{2}{*}{ Ridge Density (RD) } & \multicolumn{2}{|c|}{ Probability Densities } & \multirow[b]{2}{*}{ Likelihood Ratio } & \multicolumn{2}{|c|}{ Favored Odds } \\
\hline & Spanish $\mathrm{P}(\mathrm{RD} \mid \mathrm{C})$ & Sub-Saharan $\mathrm{P}\left(\mathrm{RD} \mid \mathrm{C}^{\prime}\right)$ & & $\begin{array}{l}\mathrm{P}(\mathrm{C})=0.5 \\
\mathrm{P}\left(\mathrm{C}^{\prime}\right)=0.5 \\
\mathrm{P}(\mathrm{C} \mid \mathrm{RD}) \\
\mathrm{P}\left(\mathrm{C}^{\prime} \mid \mathrm{RD}\right)\end{array}$ & $\begin{array}{l}\mathrm{P}(\mathrm{C})=0.7 \\
\mathrm{P}\left(\mathrm{C}^{\prime}\right)=0.3 \\
\mathrm{P}(\mathrm{C} \mid \mathrm{RD}) \\
\mathrm{P}\left(\mathrm{C}^{\prime} \mid \mathrm{RD}\right)\end{array}$ \\
\hline$<12$ & 0.01 & 0.13 & 0.077 & Spanish $(0.07)<$ sub-Sah $(0.93)$ & Spanish $(0.15)<$ sub-Sah $(0.85)$ \\
\hline 13 & 0.11 & 0.21 & 0.524 & Spanish $(0.34)<$ sub-Sah $(0.66)$ & Spanish $(0.55)>$ sub-Sah $(0.45)$ \\
\hline 14 & 0.27 & 0.29 & 0.931 & Spanish $(0.48)<$ sub-Sah $(0.52)$ & Spanish $(0.68)>$ sub-Sah $(0.32)$ \\
\hline 15 & 0.32 & 0.24 & 1.333 & Spanish $(0.57)>$ sub-Sah $(0.43)$ & Spanish $(0.76)>$ sub-Sah $(0.24)$ \\
\hline 16 & 0.21 & 0.07 & 3.000 & Spanish $(0.75)>$ sub-Sah $(0.25)$ & Spanish $(0.88)>$ sub-Sah $(0.13)$ \\
\hline$>17$ & 0.08 & 0.06 & 1.333 & Spanish $(0.57)>$ sub-Sah $(0.43)$ & Spanish $(0.76)>$ sub-Sah $(0.24)$ \\
\hline
\end{tabular}

TABLE 5-Mean of ridge density for the radial area in different studies.

\begin{tabular}{|c|c|c|c|c|c|c|c|c|c|}
\hline Males & $\begin{array}{c}\text { Caucasian-- } \\
\text { American (51) }\end{array}$ & $\begin{array}{c}\text { African- } \\
\text { American (51) }\end{array}$ & India (52) & India (54) & South India (79) & Spanish (53) & Chinese (55) & Malaysian (55) & $\begin{array}{c}\text { Our } \\
\text { Sample }\end{array}$ \\
\hline$n$ & 100 & 100 & 250 & 100 & 275 & 100 & 100 & 50 & 100 \\
\hline Mean & 11.14 & 10.9 & 12.8 & 11.05 & 12.57 & 16.23 & 11.73 & 11.44 & 14.33 \\
\hline SD & 1.31 & 1.15 & 0.9 & 1.11 & 1.49 & 1.39 & 1.07 & 0.99 & 1.22 \\
\hline Minimum & 7.90 & 8.20 & 11.00 & 9.6 & 9.50 & 13.00 & 9.3 & 9.4 & 11.4 \\
\hline Maximum & 14.70 & 14.30 & 15.00 & 12.5 & 16.40 & 19.22 & 14.9 & 14.4 & 17.53 \\
\hline
\end{tabular}

ridge density and breadth using the method described by Penrose and Loesch (45) to compare a Yoruba population sample (Nigeria) and two European Caucasian population samples. They also found significant differences between the African population studied, who presented thicker ridges, and the other two Caucasian populations, but not between the two latter populations.

Recently, some studies have conducted an empirical assessment of gender differences in epidermal ridge densities among different populations, demonstrating this to be a useful tool for inferring the donor's gender from latent fingerprints of unknown origin (51-55). However, no study to date has used this method to discriminate between human populations with different geographical origins, and thus this study is both the first in this area of research and a novelty in the field of criminalistics.

Assuming that the prior probabilities for each population are known, Bayes' theorem was used to establish the discrimination threshold between both populations. Thus, taking an equal prior probability for both populations (50\% Spanish and 50\% subSaharan), an analysis of the LR obtained for the radial and ulnar areas indicated that the discrimination threshold was a ridge count of 14 ridges $/ 7.07 \mathrm{~mm}$. Nevertheless, it should be noted that conclusions based on the likelihood ratios and posterior probabilities obtained using Bayes' theorem are simply inferences based on the population studied, when prior probabilities are assumed. Therefore, the posterior probabilities should only be applied in those cases where the ethnic origin of the possible donor is known.

The results for the radial area are the only ones which can be compared with other populations in addition to the Spanish population, as this is the only area which has been assessed in published studies using the same ridge count methodology $(51,52,54,55,78,79)$ (Table 5). Of these, only the study by Acree (51) provides data on a population of African origin (AfroAmerican), where the mean found for ridge density in the radial area was lower than that found in our study of a sub-Saharan population. These differences may possibly be determined, to some extent, by methodological variations in the selection of the count area and the method used to obtain fingerprints (rolled or plain prints). Nonetheless, it is expected that a significant portion of the differences are due to intrinsic characteristics of the populations studied. To avoid methodological differences, we have standardized the position of the count areas, allowing us to assert that the significant differences found between the Spanish and sub-Saharan populations are due only to population differences. We therefore consider it to be important to clearly define the location of the ridge count area to carry out comparative studies of any kind. This is particularly relevant in view of the forensic applications of this feature for inferring the gender or ethnicity of an individual from fingerprints of an unknown origin. More research is required to assess the extent and causes of population 
differences, as well as to increase our understanding of this and other dermatoglyphic characteristics. Increased knowledge about papillary ridge variations in human populations allows its use in a forensic context to discriminate between populations.

As with the results mentioned earlier, the results obtained in this study are of interest for their applications in the field of forensic science, to improve personal identification from fingerprint impressions. The main way in which this research contributes to current forensic concerns is by providing additional information to assess the weight of the evidence, in terms of likelihood ratio, that could help the fingerprint expert (criminal investigator) to direct the search toward the most probable group of suspects. The likelihood ratio method is a logical and scientific test that takes into account the weight of the evidence as well as other information in the case. The method is transparent and is currently being implemented in different laboratories in the field of criminalistics at the international level. In addition, this technique could prove useful in analyzing impressions that until now have not been recovered or considered for examination because of their low quality, but for which it is possible to count the ridges, particularly in cases where sub-Saharan and Spanish populations have been involved.

\section{Conclusions}

Topological differences exist in the epidermal ridge density observed in fingerprint impressions taken from a sub-Saharan population sample, with a higher density in the distal region of the finger than the proximal region.

For both hands, the ring fingers presented the narrowest ridges and the thumbs, the thickest.

Significant differences between the sub-Saharan population studied and the reference Spanish sample were found for ridge density in the distal region of the fingers, with thicker ridges in this area.

The differences observed between the sub-Saharan and Spanish samples in the distal region of the fingers, especially in the radial area, could facilitate discrimination between the populations based on the ridge density observed in a fingerprint impression.

The results presented here are new in this field of study for the African population.

\section{Acknowledgments}

This study was conducted in collaboration with the Judicial Police Unit at the Civil Guard Headquarters (Unidad Orgánica de la Policốa Judicial de la Comandancia de la Guardia Civil) in Granada (Spain). We are grateful to Dr. Ortuño and to the anonymous reviewers for their valuable suggestions, which have contributed to the enhancement of the quality of this article.

\section{References}

1. Cummins H, Midlo C. Finger prints, palms and soles. Philadelphia, PA: Blakiston, 1943.

2. Meier RJ. Anthropological dermatoglyphics: a review. Yearbook Phys Anthrop 1980;23:147-78.

3. Segura-Wang M, Barrantes R. Dermatoglyphic traits of six Chibchaspeaking Amerindians of Costa Rica, and an assessment of the genetic affinities among populations. Rev Biol Trop 2009;57(1):357-69.

4. Jantz RL. Anthropological dermatoglyphic research. Ann Rev Anthropol 1987;16:161-77.
5. Durham NM, Plato CC. Trends in dermatoglyphic research. Dordrecht, The Netherlands: Kluwer Academic Publishers, 1990.

6. Holt SB. The genetics of dermal ridges. Springfield, IL: Charles C. Thomas, 1968.

7. Loesch DZ. Quantitative dermatoglyphics: classification, genetics, and pathology. New York, NY: Oxford University Press, 1983.

8. Relethford JH, Blangero J. Detection of differential gene flow patterns of quantitative variation. Hum Biol 1990;62:5-25.

9. Relethford JH. The use of quantitative traits in anthropological genetic studies of population structure and history. In: Grawford $M$, editor. Anthropological genetics. Theory, methods and applications. Cambridge, UK: Cambridge University Press, 2007; 187-209.

10. Crawford MH, Duggirala R. Digital dermatoglyphic patterns of Eskimo and Amerindian populations: relationships between geographic, dermatoglyphic, genetic and linguistic distances. Hum Biol 1992;64:683-704.

11. Lin PM, Enciso VB, Crawford MH. Dermatoglyphic inter- and intrapopulation variation among indigenous New Guinea groups. J Hum Evol 1983;12:103-23.

12. Blangero J. Population structure analysis using polygenic traits: estimation of migration matrices. Hum Biol 1990;62:27-48.

13. Schaumann B, Alter M. Dermatoglyphics in medical disorders. New York, NY: Springer-Verlag, 1976.

14. Grande R. Development of the dermopapillary patterns from 16th to the 28th week of gestation. In: Salvatori B, Bacchi-Modena A, editors. Poor intrauterine fetal growth. Roma, Italy: Centro Minerva Médica, 1977;295 $-6$.

15. Plato CC, Garruto RM, Schaumann BA, Paul NW, editors. Dermatoglyphics: science in transition. New York, NY: John Wiley and Sons Ltd., 1991.

16. Fañanas L, van Os J, Hoyos C, McGrath J, Mellor CS, Murray R. Dermatoglyphic a-b ridge count as a possible marker for developmental disturbance in schizophrenia: replication in two samples. Schizophr Res 1996;20:307-14.

17. Rosa A, Fañanas L, Bracha SH, Torrey FE, Vanos J. Congenital dermatoglyphic malformations and psychosis: a twin study. Am J Psychiatry 2000;157(9):1511-3.

18. Galton F. Finger prints. London, UK: MacMillan, 1892.

19. Dankmeijer J, Waltman JM, DeWilde AG. Biological foundations for forensic identifications based on fingerprint. Acta Morphol Neerl Scand 1980;18:67-83.

20. Champod C, Lennard C, Margot P, Stoilovic M. Fingerprints and other ridge skin impressions. Washington, DC: CRC Press, 2004.

21. Neumann C, Champod C, Puch-Solis R, Egli N, Anthonioz A, Meuwly $\mathrm{D}$, et al. Computation of likelihood ratios in fingerprint identification for configurations of three minutiae. J Forensic Sci 2006;51(6):1255-66.

22. Neumann C, Champod C, Puch-Solis R, Egli N, Anthonioz A, BromageGriffiths A. Computation of likelihood ratios in fingerprint identification for configurations of any number of minutiae. J Forensic Sci 2007;52 (1):54-64.

23. Jamieson A, Moenssens A. Wiley encyclopedia of forensic science. West Sussex, UK: John Wiley and Sons Ltd., 2009.

24. Committee on Identifying the Needs of the Forensic Sciences Community, National Research Council. Strengthening forensic science in the United States: a path forward. Washington, DC: The National Academies Press, 2009.

25. Faigman DL, Saks JMJ, Sanders J, Cheng EK. Modern scientific evidence: standards, statistics and research methods, student edn. New York, NY: Thomson West-Foundation Press, 2008.

26. Okajima M. Development of dermal ridges in the fetus. J Med Genet $1975 ; 12(3): 243-50$.

27. Okajima M. Dermal and epidermal structures of the volar skin. In: Wertelecki W, Plato CC, editors. Dermatoglyphics fifty years later. New York, NY: Alan R. Liss, 1979;179-98.

28. Babler WJ. Qualitative differences in morphogenesis of human epidermal ridges. In: Wertelecki W, Plato CC, editors. Dermatoglyphic fifty year later. New York, NY: Alan R. Liss, 1979;199-208.

29. Babler WJ. Prenatal development of dermatoglyphic digital patterns: associations with epidermal ridge volar pad and bone morphology. Coll Anthropol 1987;11(2):297-303.

30. Babler WJ. Prenatal communalities in epidermal ridge development. In: Durhan NM, Plato CC, editors. Trends in dermatoglyphic research. Dordrecht, The Netherlands: Kluwer Academic Publishers, 1991;54-68.

31. Seidenberg-Kajabova H, Pospisilova V, Vranakova V, Varga I. An original histological method for studying the volar skin of the fetal hands and feet. Biomed Pap Med Fac Univ Palacky Olomouc Czech Repub 2010;154(3):211-8 
32. Loesch DZ, Godlewska J. Breadth of the dermal ridges in the a-b area in children aged 0-6 years. Folia Morphol (Warsz) 1971;30:511-4.

33. Loesch DZ, Czyżewska J. Breadth of the dermal ridges in the a-b area in children aged 0-14 years. Folia Morphol (Warsz) 1972;31:249-54.

34. David TJ. Distribution, age and sex variation of the mean epidermal ridge breadth. Hum Hered 1981;31:279-82.

35. Modi SK, Elliott SJ. Impact of image quality on performance: comparison of young and elderly fingerprints. Proceedings of the 6th International Conference on Recent Advances in Soft Computing (RASC); 2006 July 10-12; Canterbury, UK: University of Kent, 2006; 449-54.

36. Mavalwala J. Dermatoglyphics: an international bibliography. The Hague, The Netherlands/Paris, France: Mouton Publishers, 1977.

37. Dermatoglifos Figueras I. Bibliografốa. Portugal, Spain: Departamento de Antropologốa de la Universidad de Coimbra, 1993.

38. Kumbnani HK. Dermatoglyphics: a review. In: Bhasin V, Bhasin MK, editors. Anthropology today: trends, scope and applications. Delhi, India: Kamla-Raj Enterprises, 2007;285-95.

39. Okajima M. Frequency of fork in epidermal-ridge minutiae in the finger print. Am J Phys Anthropol 1970;32:41-8.

40. Stoney DA, Thornton JL. A method for the description of minutia pairs in epidermal ridge patterns. J Forensic Sci 1986;31(4):1217-34.

41. Sarkar NC. Finger ridge minutiae: classification distribution and genetics. Anthropological Survey of India. Calcuta, India: Anthropological Survey of India, 2004.

42. Santamarốa FA. A new method for evaluating ridge characteristics. Fingerprint Ident Mag 1955;36:3-8, 16-8.

43. Gutiérrez-Redomero E, Galera V, Martốnez JM, Alonso C. Biologica variability of the minutiae in the fingerprints of a sample of the Spanish population. Forensic Sci Int 2007;172:98-105.

44. Gutiérrez-Redomero E, Alonso-Rodrốguez C, Hernández-Hurtado LE, Rodrốguez-Villalba JL. Distribution of the minutiae in the fingerprints of a sample of the Spanish population. Forensic Sci Int 2011;208:79-90.

45. Penrose LS, Loesch D. A study of dermal ridge width in the second (palmar) interdigital area with special reference to aneuploid states. J Ment Defic Res 1967;11:36-42.

46. Cummins H, Waits WJ, McQuitty JT. The breadths of epidermal ridges on the finger tips and palms: a study of variation. Am J Anat 1941;68:127-50.

47. Ohler EA, Cummins H. Sexual differences in breadths of epidermal ridges on finger tips and palms. Am J Phys Anthropol 1942;29(3): 341-62.

48. Loesch DZ, Lafranchi M. Relationship of epidermal ridge patterns with body measurements and their possible evolutionary significance. Am J Phys Anthropol 1990;82:183-9.

49. Králốk M, Novotný V. Epidermal ridge breadth: an indicator of age and sex in paleodermotoglyphics. Variab Evol 2003;11:5-30.

50. Badawi A, Mahfouz M, Tadross R, Jantz R. Fingerprint based gender classification. In: Arabnia HR, editor. Proceedings of the 2006 International Conference on Image Processing, Computer Vision, and Pattern Recognition; 2006 June 26-29; Las Vegas, NV. Athens, GA: CSREA Press, 2006; 41-6.

51. Acree MA. Is there a gender difference in fingerprint ridge density? Forensic Sci Int 1999;102:35-44.

52. Gungadin S. Determination from fingerprint ridge density. Internet $\mathrm{J}$ Med Update 2007;2(2):1-7.

53. Gutiérrez-Redomero E, Alonso C, Romero E, Galera V. Variability of fingerprint ridge density in a sample of Spanish Caucasians and its application to sex determination. Forensic Sci Int 2008;180:17-22.

54. Nayak VC, Rastogi P, Kanchan T, Lobo SW, Yoganarasimha K, Nayak $\mathrm{S}$, et al. Sex differences from fingerprint ridge density in the Indian population. J Forensic Leg Med 2010;17:84-6.

55. Nayak VC, Rastogi P, Kanchan T, Yoganarasimha K, Kumar GP, Menezes RG. Sex differences from fingerprint ridge density in Chinese and Malaysian population. Forensic Sci Int 2010;197:67-9.

56. Frick MD, Modi SK, Elliont SJ, Kukuka EP. Impact of gender on fingerprint recognition system. Proceedings of the 5th International Conference on Information Technology and Applications (ICITA); 2008 June 26-28; Queensland, Australia. Bathurst, NSW: Macquarie Scientific Publishing, 2008; 717-21.
57. Penrose LS. Memoradum on dermatoglyphics nomenclanture. Birth Defects Original Article Series 1968;4:1-13.

58. Grieve MC, Dunlop J. A practical aspect of the Bayesian interpretation of fibre evidence. J Forensic Sci Soc 1992;32:169-75.

59. Jantz RL, Owsley DW. Factor analysis of finger ridge-counts in Blacks and Whites. Ann Hum Biol 1977;4(4):357-66.

60. Jantz RL, Hawkinson CH. Finger ridge-count variability in sub-Saharan Africa. Ann Hum Biol 1979;6(1):41-53.

61. Jantz RL, Hawkinson CH, Brehme H, Hitzeroth HW. Finger ridge-count variation among various sub-Saharan Africa groups. Am J Phys Anthropol 1982;57:311-21.

62. Kamali MS. Mean epidermal ridge breadth among the 12 Iranian endogamous groups. Indian J Phys Anthropol Hum Genet 1984;10(3-4): $150-4$.

63. Arrieta M, Ibarrondo M, Lostao C. Digital dermatoglyphics in the Basque population: univariate and multivariate comparisons with other Spanish populations. Am J Phys Anthropol 1987;73:89-98.

64. Arrieta M, Criado B, Martốnez B, Simon A, Salazar L, Lostao C. Characterization of digital dermatoglyphic features in Salazar valley: comparison with other Basque valleys. Ann Hum Biol 1991;18:221-33.

65. Kandil M, Luna F, Chafik A, Zaoui D, Moral P. Digital dermatoglyphic patterns of Moroccan Arabs: relationships with Mediterranean populations. Ann Hum Biol 1998;25(4):319-29.

66. Chamla MC. La Répartition géographique des crêstes papillaires digitales dans le monde: Nouvel essai de synthèse. d'Anthropol 1962;66:526 -41 .

67. Keita BN. Les dermatoglyphes digitaux et palmaires des principaux groupes ethniques du Mali. Bull Mém Soc d'Anthropol Paris Série XIII $1981 ; 8(1): 25-42$.

68. Sunderland E, Coope E. The tribes of south and central Ghana: a dermatoglyphics investigation. Man New Series 1973;8(2):228-65.

69. Ritgers-Aris CAE. Dermatoglyphics of three west African tribes (Fali-Cameroon, Kusasi-Ghana, Baoule-Ivory Coast): I. Digital patterns. Proc Koninklijke Nederl Akad Wetensch Ser C 1975;68:47-57.

70. Jantz RL, Brehme H. Finger and palmar dermatoglyphics of a Yoruba (Nigeria) sample. Ann Hum Biol 1978;5(6):539-46.

71. Vecchi F. Geographical variation of digital dermatoglyphics in Africa. Am J Phys Anthropol 1981;54:565-80.

72. Igbigbi PS, Didia BC, Agan TU, Ikpae BE. Palmar and digit dermatoglyphics in two ethnic communities in Nigeria. West Afr J Anatomy 1994;2:52-6.

73. Igbigbi PS, Didia BC, Owhojedo H, Obochi O. Comparative palmar and digital dermatoglyphics of Hausa and Urhobo ethnic groups in Nigeria. West Afr J Anatomy 1996;4:51-6.

74. Igbigbi PS, Msamati BC. Palmar and digital dermatoglyphic traits of Kenyan and Tanzanian subjects. West Afr J Med 2005;24(1):26-30.

75. Boroffice RA. Digital dermatoglyphic patterns in a sample of the Nigerian population. Am J Phys Anthropol 1978;49(2):167-70.

76. Jaja BNR, Igbigbi PS. Digital and palmar dermatoglyphics of the Ijaw of Southern Nigeria. Afr J Med Med Sci 2008;37:1-5.

77. Jantz RL, Parham KR. Racial differences in dermal ridge breadth. Hum Biol 1978;50:33-40.

78. Krishan K, Ghosh A, Kanchan T. Sex differences in fingerprint density. Causes and further observations. J Forensic Leg Med 2010;17:172-3.

79. Nithin MD, Manjunatha B, Preethi DS, Balaraj BM. Gender differentiation by finger ridge count among South Indian population. J Forensic Leg Med 2011;18(2):79-81.

Additional information and reprint requests:

Esperanza Gutiérrez-Redomero, Ph.D.

Departamento de Zoología y Antropología Física

Instituto Universitario de Investigación en Ciencias Policiales

Universidad de Alcalá

Alcalá de Henares 28871

Madrid

Spain

E-mail: esperanza.gutierrez@uah.es 